\title{
Effect of Spool Shape Design on Gas Turbine Engine Electro-Hydraulic Valve Performance
}

\author{
Mahmoud M Adel ${ }^{1}$, Mohamed A Metwally ${ }^{2}$, and Ashraf Abdel Badee Ghorab ${ }^{3}$ \\ Egyptian armed forces ${ }^{1}$, Military Technical College ${ }^{2}$ and Ain Shams University ${ }^{3}$ \\ Faculty of Engineering, Department of Mechanical Power \\ Ain Shams University \\ Cairo, Egypt
}

\begin{abstract}
The main parts of the gas turbine engine are the compressor, combustor, turbine, and control units. Sometimes the ground equipment gas turbine engine encounters a problem in the control unit that can badly affect the engine's performance at different operating regimes. Consequently, a drastic decrease in engine lifetime and reliability is noticed. The main affecting parameters are the air control system, combustion, and compression systems of the gas turbine engine. Therefore, the airflow control system is one of the important parameters that affect the gas turbine engine's dynamic performance. So, the dynamic performance of the engine air control system has to be investigated. Controlling the dynamic performance of the engine air control system relies; heavily on electrohydraulic systems. Among the most common and challenging problems with electro-hydraulic control systems is investigating the effect of changing the design geometry, including shapes, of their components.

This paper presented a spool in an Electro-Hydraulic Servo Valve (EHSV) in a turboshaft engine as an example. A detailed analysis of a fuel-based electrohydraulic position control device was presented here in this paper. To assess the implications of shape modifications on the dynamic performance of the system behavior, three distinct shapes for this spool were investigated. ANSYS FLUENT 19.2 was used for modeling and CFD study of the three shapes of the spool at four different openings. The outcomes were compared with each other.

The results showed that using a three-step spool is a better design and selection than using one or two steps. There was a reduction in pressure resonance and a smoothing of the velocity of the fluid inside the valve. So, the dynamic performance of the valve will be improved by reducing the pressure resonance and reducing the jet of fluid flow at the valve inlet, vortices, and smoothness in the moving spool. Also, the performance of the IGV will be improved. As a result, the good dynamic performance of the gas turbine will be obtained.
\end{abstract}

Key Words: Servo solenoid valve, Electrohydraulic servo valve, Valve spool geometry, Valve performance, Position control, Valves, Directional control valves, Spool valve, Computational Fluid Dynamics.

\section{INTRODUCTION}

\subsection{System Description}

The system under study is part of the fuel management and control system of air gas turbine engine of ground equipment. Here, our interest is the (EHSV) system, which exactly controls the inlet guide vanes of the engine through an actuator. Fig. 1 shows the functional scheme of the studied (EHSV). The system derived by pump (1) runs on diesel fuel (DF-2). Pump pressure is regulated by means of a pressure regulator valve. The regulated pressure is pumped into a directional control valve (4). The valve's spool (5) movement controls the direction and the flow rate comes out from the valve to the actuator (11). The spool movement governed by a stroke controlled proportional solenoid (3) in a contactless manner. 


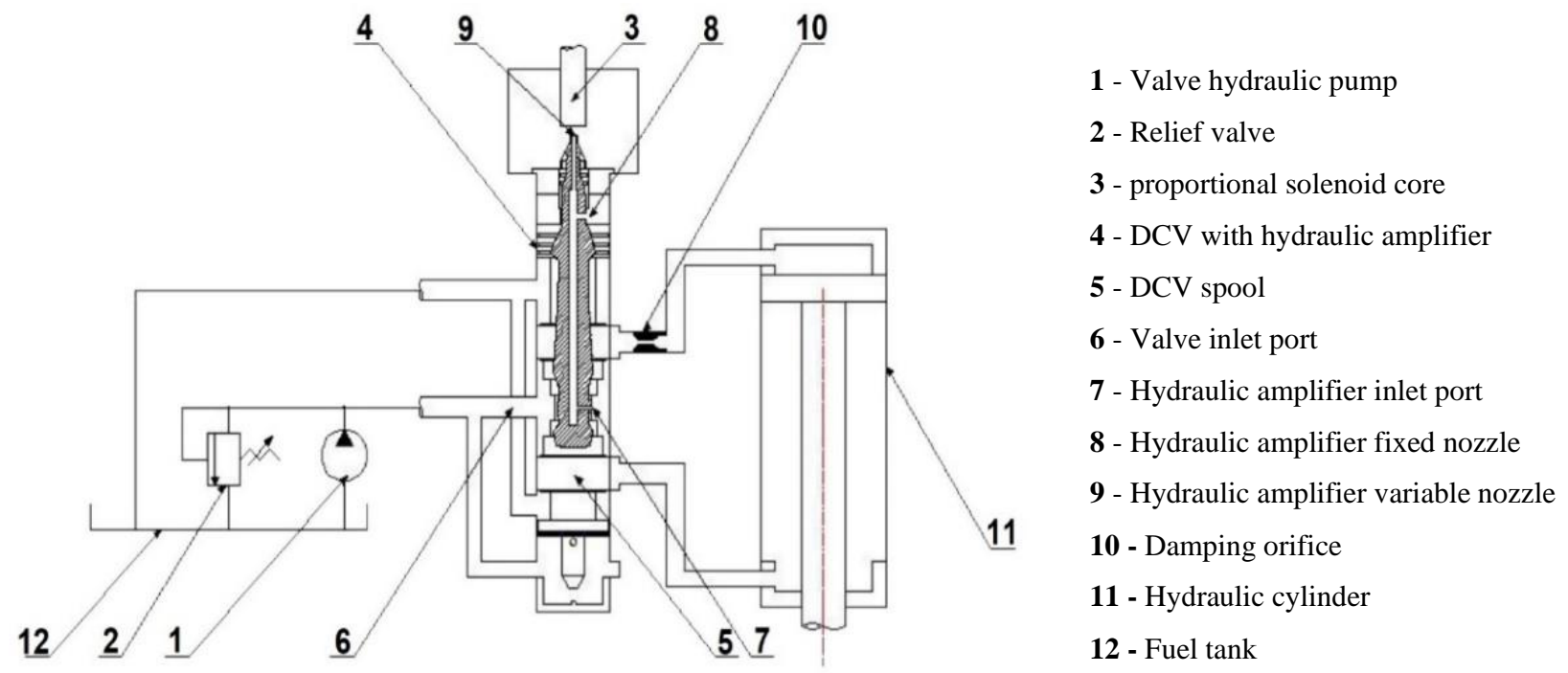

Fig. 1: Scheme of the studied EHSV

The spool incorporates a hydraulic amplifier (7) controlled by the width of the gab separating the amplifier nozzle (9) and the solenoid core (3). The amplifier acts as a pressure reducer with a fixed orifice (8) and a variable nozzle (9). The change in the gap width leads to a variable nozzle area, which in turn changes the pressure on the upside of the spool (5). On the other hand, the supply pressure conducts a constant pressure force on the down side of the spool all the time. The spool is moved by the difference in pressure forces on the spool's up and down sides in order to keep the gap width constant. The hydraulic amplifier is used to convert the small solenoid core displacement into a considerable pressure force to move the spool.

\subsection{Problem definition}

This paper was presented to study the dynamic performance of this valve, which has an effect on the dynamic performance of the gas turbine engine Fig. 2. The internal design of the valve under study has a great effect on the valve's dynamic performance. By inspection, it has been found that its internal design geometry was not an ordinary shape, but a three-step shape as shown in Fig. 6 . The internal design has to be changed and inspected for its effect on the dynamic performance (if the change in shape enhances the dynamic performance or not).

\section{LITERATURE REVIEW}

Metwally et al. [1] studied the dynamic behaviour of an electrohydraulic servo actuator, theoretically and practically. Samy et al. [2] derived a mathematical dynamic model and solved it using SIMULINK, a Matlab® application to model the nonlinearity of fluid behaviour due to special shaped orifices. Lisowski et al. [3] proposed utilising a logic-sort directional control valve instead of a spool-type directional control valve. Lisowski et al. [4] also proposed using 3D CFD modelling to calculate flow forces operating on the spool of a solenoid-operated directional control valve. Pan et al. [5] utilised CFD to examine the discharge characteristics of a servo-valve spool valve. Posa et al. [6] studied flow via a directional valve with a closed centre (4/3). The flow has been simulated in a 2D computational domain. Amirante et al. [7] used a detailed numerical analysis to construct a 3D numerical simulation to cope with the driving forces operating on a $4 / 3$ hydraulic open-centre directional control valve spool. Furthermore, an experimental approach for determining a spool valve's discharge coefficient as a function of opening and pressure drop has been proposed by Viall et al. [8]. Ji et al. [9] established pressure distribution and noise measurement test equipment for a hydraulic valve, Ji et al. [10] found that the direction of steady flow force in the non-circular opening spool valve changes with the shift of the flow direction on the notch pass. Ye et al. [11] constructed a dynamic model to analyse the dynamic features of a pilot-operated two-stage solenoid valve utilised in a pneumatic system. The flow inside a pressure-regulating valve has been investigated at various valve openings and pressure drops by Chattopadhyay et al. [12]. The performance, flow patterns, and cavitation phenomena of a ball valve were studied experimentally by Chern et al. [13]. Amirante et al. [14] investigated the fluid dynamic behaviour of a commercial hydraulic proportional valve. Borghi et al. [15] applied a numerical analysis based on CFD to demonstrate three distinct valve port connections. Yang et al. [16] addressed the flow force inside hydraulic spool valves. Simulations were carried out to study the efflux angles. The influence of the throttling groove structure on cavitation noise was investigated by Du, X. et al. [17]. Ye, Yi et al. [18] aimed to clarify the effects of the groove shape on the flow characteristics through CFD. 
International Journal of Advances in Scientific Research and Engineering (ijasre), Vol 8 (2), February -2022

\section{THE ELECTRO HYDRAULIC VALVE'S NONLINEAR MATHEMATICAL MODEL}

In this section, the flow equations through the valve, the continuity equation, and the equation of motion of the spool were derived.

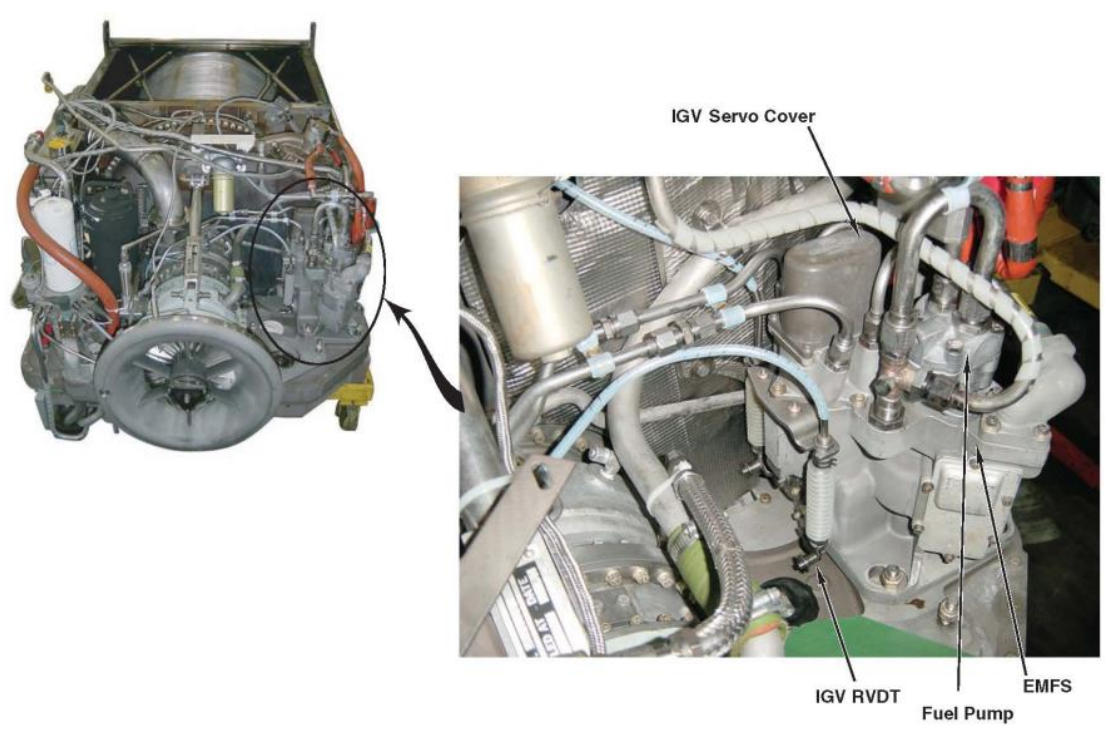

Fig. 2: Electro-Mechanical Fuel System (EMFS) / Inlet Guide Vane Interface

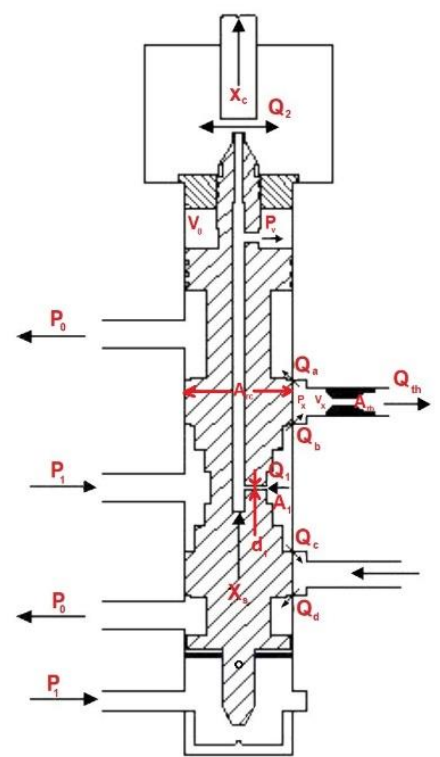

Fig. 3: Hydraulic amplifier

Fuel flow rates through the two restrictions of the hydraulic amplifier shown in Fig. $\mathbf{3}$ are given by:

$$
\begin{aligned}
& Q_{1}=C_{d} A_{1} \sqrt{\frac{2}{\rho}\left(P_{1}-P_{v}\right)} \\
& Q_{2}=C_{d} A_{\mathbf{n}} \sqrt{\frac{2}{\rho}\left(P_{v}-P_{0}\right)} \\
& \mathbf{A}_{1}=\frac{\pi}{4} \mathbf{d}_{1}^{2} \quad \mathbf{A}_{\mathbf{n}}=\pi * \operatorname{gap} \quad \operatorname{gap}=\left(\mathbf{x}_{\mathbf{i}}+\mathbf{x}_{\mathbf{c}}-\mathbf{x}_{\mathbf{s}}\right)
\end{aligned}
$$

Where $\left(\boldsymbol{Q}_{\mathbf{1}}, \mathbf{A}_{\mathbf{1}}, \boldsymbol{Q}_{2}, \mathbf{A}_{\mathbf{n}}, \mathbf{X}_{\mathbf{i}}, \boldsymbol{P}_{\mathbf{1}}, \boldsymbol{P}_{\mathbf{0}}, \boldsymbol{\rho}, \boldsymbol{C}_{\boldsymbol{d}}, \mathbf{X}_{\mathbf{s}}\right)$ are the amplifier inlet port flow rate and area, the amplifier variable nozzle flow rate and area, the initial gap between solenoid and spool, valve supply and return pressures, fuel density, discharge coefficient, and spool displacement.

The continuity equation applied to the hydraulic amplifier chamber, neglecting the hydraulic losses in the amplifier bore, could be written as:

$$
\boldsymbol{Q}_{\mathbf{1}}-\boldsymbol{Q}_{2}+\mathbf{A}_{\mathrm{s}} \frac{\mathbf{d X}_{\mathrm{s}}}{\mathbf{d}_{\mathrm{t}}}=\frac{\mathrm{V}_{0}-\mathrm{A}_{\mathrm{s}} \mathrm{X}_{\mathrm{s}}}{\mathrm{B}} \frac{\mathrm{dP}_{\mathrm{v}}}{\mathrm{d}_{\mathrm{t}}} \quad \text { (4) } \quad \mathbf{A}_{\mathrm{s}}=\frac{\boldsymbol{\pi}}{4}\left(\mathbf{d}_{\mathrm{s}}^{2}-\mathbf{d}_{\mathrm{a}}^{2}\right)
$$

Where $\left(\mathrm{A}_{\mathrm{s}}, \mathrm{V}_{0}\right.$, B $)$ are valve spool cross sectional area, initial volume, and Bulk's modulus. The motion of the spool is governed by the following equation of motion, neglecting the static friction force:

$$
\begin{aligned}
& \boldsymbol{m}_{s} \mathbf{X}_{\mathrm{S}}^{\prime \prime}=\boldsymbol{P}_{\mathbf{1}} \boldsymbol{A}_{\boldsymbol{r}}-\boldsymbol{P}_{\boldsymbol{v}} *\left(\boldsymbol{A}_{\boldsymbol{s}}+\boldsymbol{A}_{2}\right)-\boldsymbol{f}_{\boldsymbol{s}} \mathbf{X}_{\mathrm{S}}^{\prime}-\boldsymbol{F}_{\text {sseat }}-\boldsymbol{F}_{\boldsymbol{j}}-\boldsymbol{W}_{\boldsymbol{s}} \\
& F_{\text {sseat }}= \begin{cases}\boldsymbol{k}_{\text {seat }} *\left(x_{s}-x_{\text {smin }}\right)+f_{\text {seat }} * \mathbf{X}_{\mathrm{S}}^{\prime} & x_{s} \leq x_{\text {smin }} \\
0 & x_{\text {smin }}<x_{s}<x_{\text {smax }} \\
\boldsymbol{k}_{\text {seat }} *\left(x_{s}-x_{\text {smax }}\right)+f_{\text {seat }} * \mathbf{X}_{\mathrm{s}}^{\prime} & x_{s} \geq x_{\text {smax }}\end{cases}
\end{aligned}
$$




$$
\boldsymbol{F}_{j}= \begin{cases}\frac{\rho * Q_{b}^{2}}{C_{C} A_{b}}+\frac{\rho * Q_{d}^{2}}{C_{C} A_{d}} & \boldsymbol{x}_{s}>\mathbf{0} \\ \frac{\rho * Q_{a}^{2}}{C_{C} A_{a}}+\frac{\rho * Q_{c}^{2}}{C_{C} A_{c}} & \boldsymbol{x}_{s}<\mathbf{0}\end{cases}
$$$$
W_{s}=m_{s} g
$$

The spool displacement is limited mechanically by a limiter at the end of its stroke on both sides. When reaching any of the side limiters, the seat reaction develops a counter force, $\boldsymbol{F}_{\text {sseat }}$, given by equation (7).

As a result of fluid flow, a jet reaction force, $\mathrm{Fj}$, equal to the rate of change of the momentum of the fluid is generated in equation (8). Also, because of the vertical position of the valve, the weight of the spool effects its displacement as described by equation (15).

Where ( $\left.\mathbf{m}_{\mathrm{s}}, \mathbf{A}_{\mathrm{r}}, \mathbf{A}_{2}, \mathbf{f}_{\mathrm{s}}, \boldsymbol{F}_{\boldsymbol{j}}, \mathbf{F}_{\text {sseat }}, \mathbf{W}_{\mathrm{s}}, \mathbf{x}_{\mathrm{smin}}, \mathbf{x}_{\mathrm{smax}}, \mathbf{c}_{\mathrm{c}}\right)$ are the spool's mass, the rear cap and nozzle bore areas, the spool damping coefficient, the jet reaction and the seat reaction forces, the spool's weight, the spool's minimum and maximum displacement limits, and the contraction coefficient.

where $\left(Q_{a}, Q_{b}, Q_{c}, Q_{d}, A_{a}, A_{b}, A_{c}, A_{d}\right)$ are port openings (a, b, c, \& d) flow rates and areas.

Neglecting the losses through the transmission lines, which connect the valve to the actuator, the flow rates through the valve restriction areas are given by:

$$
\begin{aligned}
& \boldsymbol{Q}_{\boldsymbol{a}}=\boldsymbol{C}_{\boldsymbol{d}} \boldsymbol{A} \boldsymbol{a} \sqrt{\frac{2}{\boldsymbol{\rho}}\left(\boldsymbol{P}_{\mathrm{X}}-\boldsymbol{P}_{0}\right)} \\
& \boldsymbol{Q}_{\mathrm{c}}=\boldsymbol{C}_{\boldsymbol{d}} \boldsymbol{A}_{\mathrm{c}} \sqrt{\frac{2}{\boldsymbol{\rho}}\left(\boldsymbol{P}_{1}-\boldsymbol{P}_{\mathrm{B}}\right)} \\
& \boldsymbol{Q}_{\mathrm{th}}=\boldsymbol{C}_{\boldsymbol{d}} \boldsymbol{A}_{\mathrm{th}} \sqrt{\frac{2}{\boldsymbol{\rho}}\left(\boldsymbol{P}_{\mathrm{x}}-\boldsymbol{P}_{\mathrm{A}}\right)}
\end{aligned}
$$

$$
\begin{aligned}
& \boldsymbol{Q}_{\mathrm{b}}=\boldsymbol{C}_{\boldsymbol{d}} \boldsymbol{A}_{\mathrm{b}} \sqrt{\frac{2}{\boldsymbol{\rho}}\left(\boldsymbol{P}_{1}-\boldsymbol{P}_{\mathrm{x}}\right)} \\
& \boldsymbol{Q}_{\mathrm{d}}=\boldsymbol{C}_{\boldsymbol{d}} \boldsymbol{A}_{\mathrm{d}} \sqrt{\frac{2}{\rho}\left(\boldsymbol{P}_{\mathrm{B}}-\boldsymbol{P}_{0}\right)}
\end{aligned}
$$

The valve restriction areas can be classified into radial clearance areas and port opening areas. The radial clearance area is calculated in equation (15). The port opening area, as illustrated in Fig. 4, can be described by equations (16) and (17).

$$
\boldsymbol{A}_{\boldsymbol{a}, \boldsymbol{b}, \boldsymbol{c}, \boldsymbol{d}} \begin{cases}\left\{\begin{array}{l}
\boldsymbol{A}_{a}=\boldsymbol{A}_{c}=\boldsymbol{A}_{r c}=\pi\left(D_{s}+c\right) c \\
A_{b}=A_{d}=A_{x s}+A_{r c}
\end{array}\right. \\
\begin{cases}A_{a}=A_{c}=A_{x s}+A_{r c} \\
A_{b}=A_{d}=A_{r c}\end{cases} \end{cases}
$$

$$
A_{x s}=4 * A_{x s} \mid p
$$

$$
\begin{aligned}
& \boldsymbol{A}_{\boldsymbol{x} s} \mid \boldsymbol{p}=\mathbf{r}_{\mathrm{p}}^{2} * \cos ^{-1}\left(\frac{r_{p}-\left|x_{s}\right|}{r_{p}}\right)-\left(r_{p}-\left|x_{s}\right|\right) * \sqrt{2 * r_{p} *\left|x_{s}\right|-x_{s}^{2}} \\
& \mathbf{A}_{\mathrm{th}}=\frac{\boldsymbol{\pi}}{4} \mathbf{d}_{\mathrm{th}}^{2}
\end{aligned}
$$

Where $\left(\mathrm{P}_{\mathrm{x}}, \mathrm{P}_{\mathrm{A}}, \mathrm{P}_{\mathrm{B}}, \mathrm{r}_{\mathrm{p}}, \mathrm{A}_{\mathrm{th}}, \mathrm{A}_{\mathrm{rc}}, \mathrm{A}_{\mathrm{xs}}, \mathrm{A}_{\mathrm{xs}} \mid \mathrm{p}\right)$ are the throttle, cap side and rod side pressures and the port radius, the throttle orifice and radial clearance areas, the area of all ports opening, and the area of single port opening.

By applying the continuity equation to the valve outlet while neglecting the external leakage, equations (19) and (20) were obtained. 
International Journal of Advances in Scientific Research and Engineering (ijasre), Vol 8 (2), February -2022

$$
\begin{aligned}
& \mathbf{Q}_{\mathrm{b}}-\mathbf{Q}_{\mathbf{a}}-\mathbf{Q}_{\mathrm{th}}=\frac{v_{x}}{B} \frac{d P_{x}}{d t} \\
& \mathbf{Q}_{\mathbf{c}}-\mathbf{Q}_{\mathbf{d}}+\mathbf{Q}_{\mathrm{B}}=\mathbf{0}
\end{aligned}
$$

Where $\left(\boldsymbol{V} x, \mathbf{Q}_{\mathbf{B}}\right)$ are the throttle volume and flow rate at the valve outlet on the actuator's rod side.
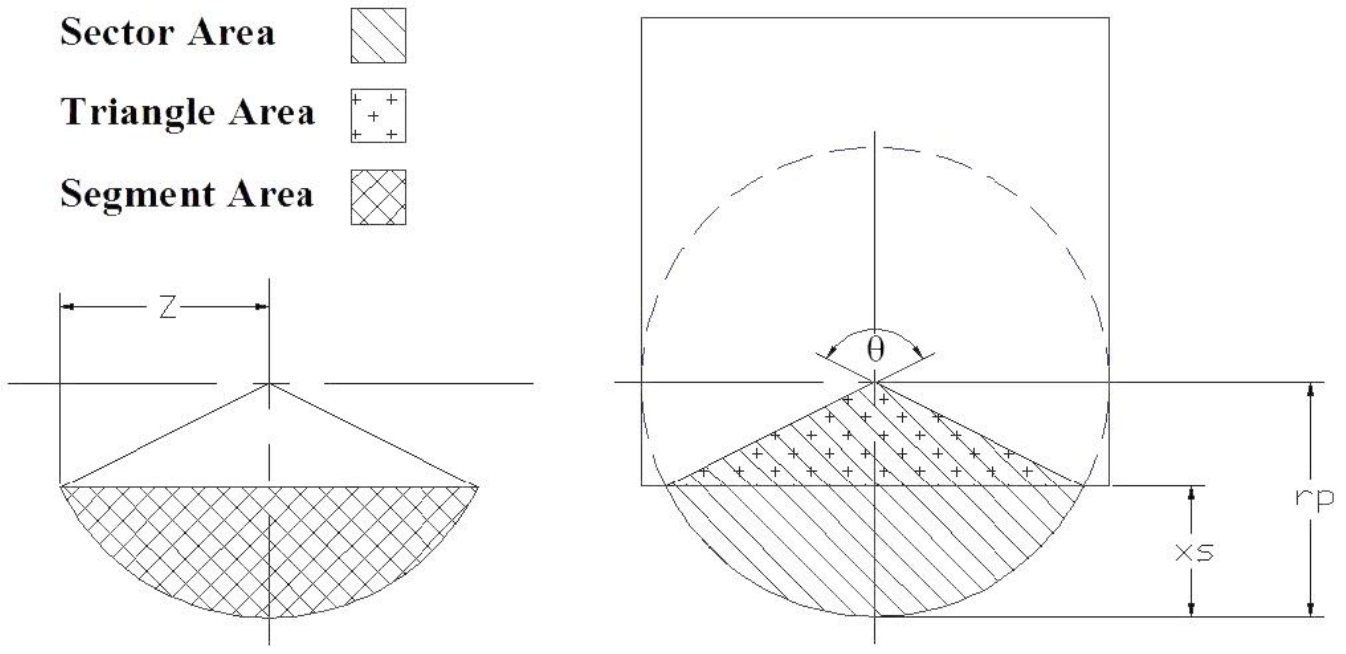

Fig. 4: Description of the valve's port opening area calculation

The nonlinear mathematical model doesn't depend on geometry; it deals with the valve as a black box. So, we have to study the design geometry.

\section{CFD ANALYSIS}

\subsection{Geometry of modeling}

The three types of spools with typical structural features are shown in Fig. 5: (b) is a spool with one step, Fig. 5: (c) is a spool with two steps, and Fig. 5: (d) is a spool with three steps with a relatively complex structure. $X$ is the outlet orifice length (mm) in the axial direction of Fig. 5: (a). To demonstrate the effects of the structural features on the flow characteristics, the lengths of the outlet orifice are set to be equal to $0.25 \mathrm{D}(1.625 \mathrm{~mm}), 0.5 \mathrm{D}(3.25 \mathrm{~mm}), 0.75 \mathrm{D}(4.875 \mathrm{~mm})$, and $\mathrm{D}(6.5 \mathrm{~mm})$. Where $\mathrm{D}$ is the diameter of the outlet opening, which equals $6.5 \mathrm{~mm}$.

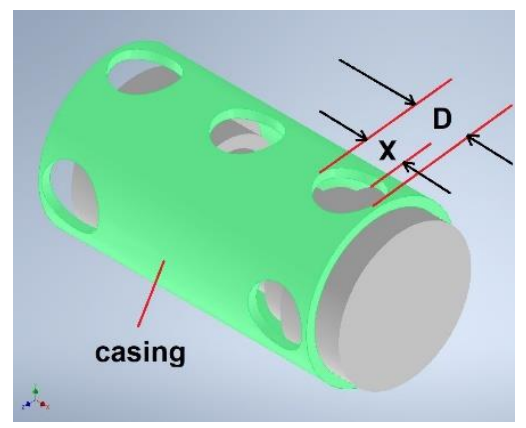

Fig. 5: (a)

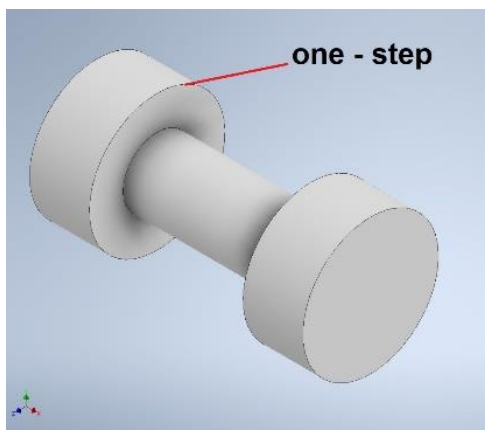

Fig. 5: (b) 
International Journal of Advances in Scientific Research and Engineering (ijasre), Vol 8 (2), February -2022

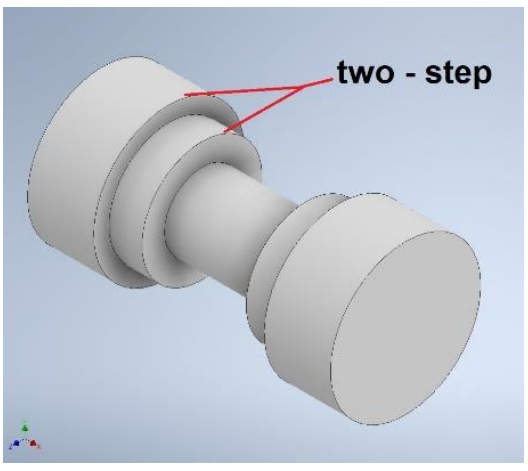

Fig. 5: (c)

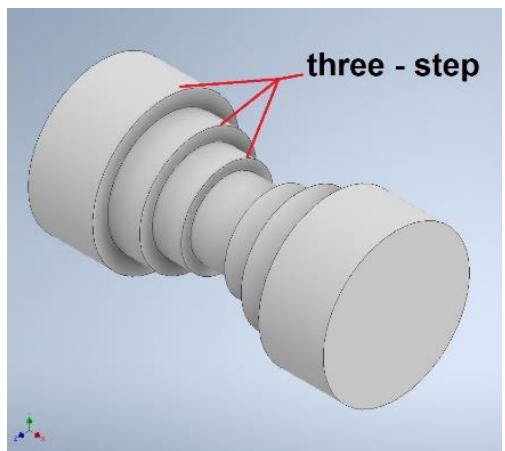

Fig. 5: (d)

Fig. 5: The geometric structures of (a) casing and spool assembly; (b) one-step shape; (c) two-step shape; and (d) three-step shape.

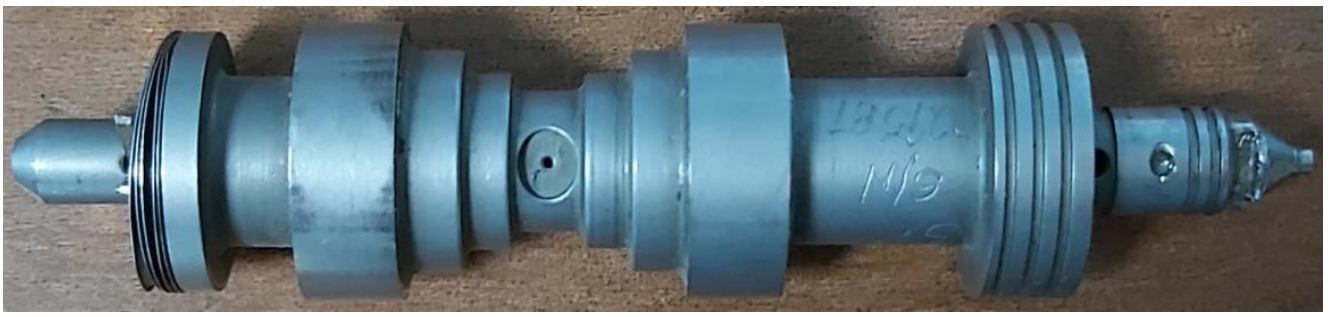

Fig. 6: The geometric structures of the studied spool

\subsection{Mesh generation (Grid model)}

Changing the spool displacement as a result of the opening changes the flow area, allowing for step-by-step control of fluid flow properties. As a result, the flow characteristics study begins with identifying the relationship between both the flow's output pressure and its input pressure. The influence of spool shape design geometry on the dynamic performance of the hydraulic valve was investigated using the CFD numerical simulation approach. The grid model was created by using the entire flow field inside the valve. It was divided by the application as shown in Fig. 7, which had roughly 107,469 cells. There are approximately 105,017 and 114,586 cells in grid models for two-step form and one-step instances, respectively.

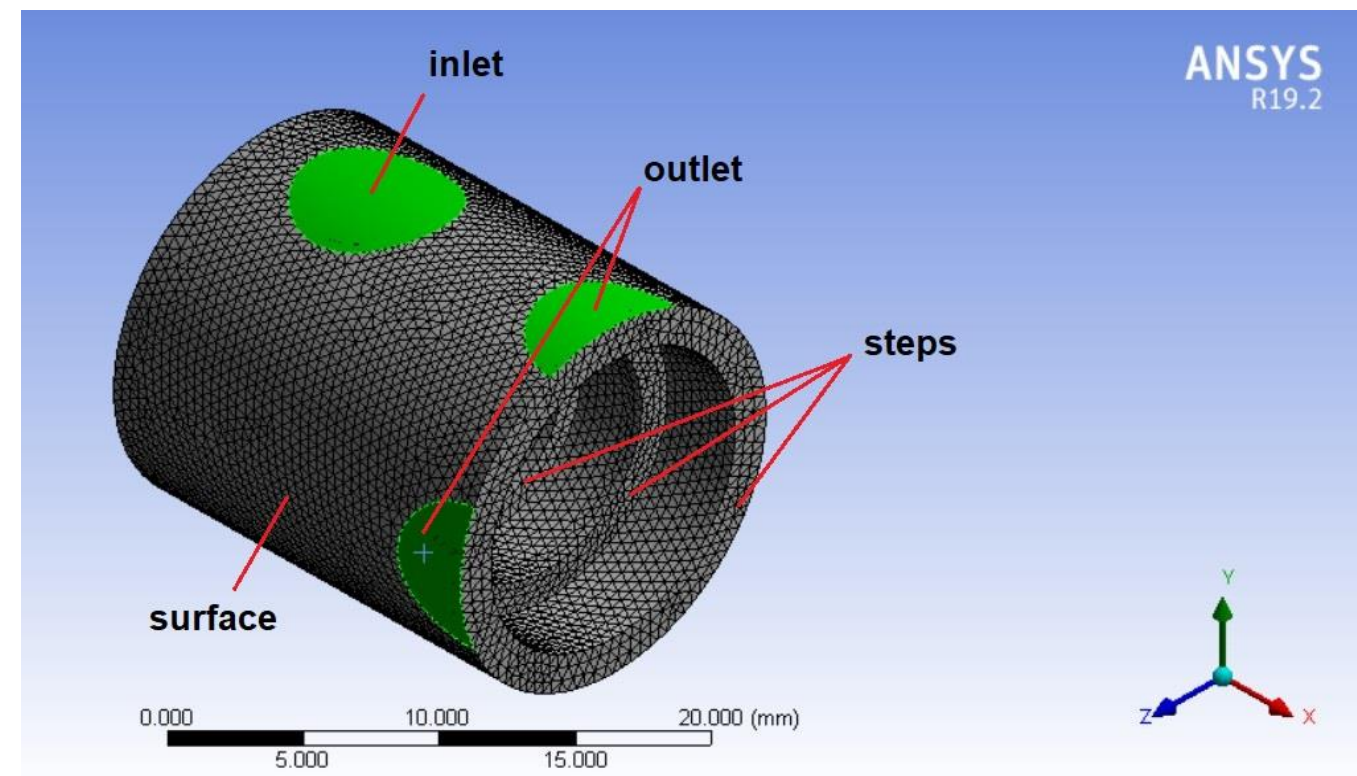

Fig. 7: Grid model for the three-step shape case. 


\subsection{Boundary conditions and operating parameters}

To perform the analysis, the Realizable k- $\varepsilon$ turbulence model was chosen from a set of models already available in ANSYS/Fluent

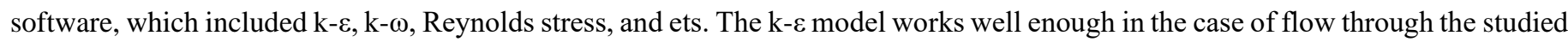
valve because there are no conditions for the formation of laminar flow in the valve. As a result, the Realizable $k-\varepsilon$ turbulence model was chosen, and inlet pressure and outlet mass flow rate boundary conditions were imposed. In addition, the solution accuracy is set to be $10^{-5}$. Hydraulic fluid (DF-2) with a viscosity of $3 \mathrm{e}^{-6} \mathrm{~kg} \cdot \mathrm{m}^{-1} \cdot \mathrm{s}^{-1}$ and a density of $800 \mathrm{~kg} \cdot \mathrm{m}^{-3}$ were chosen as the medium. Four positions $(X=1.625,3.25,4.875$, and $6.5 \mathrm{~mm}$ ) during the opening process are selected to be analyzed. The calculation has been shown for seven values of inlet pressures of hydraulic liquid (DF-2): 6,7,8,9,10,11,12 bar (pressure inlet). The mass flow rate outlet has been assumed to be equal to $0.01489 \mathrm{~kg} / \mathrm{s}$ [2] for the outlet boundary condition type.

\section{RESULTS AND DISCUSSION}

Every type of step-shape was analyzed at a certain pressure inlet $\mathrm{P}=6,7,8,9,10,11,12$ bar at four different displacements $\mathrm{X}=0.25 \mathrm{D}$, $0.5 \mathrm{D}, 0.75 \mathrm{D}$, and $\mathrm{D}$.

\section{$>$ First displacement at $\mathrm{X}=\mathbf{0 . 2 5 \mathrm { D }}(\mathbf{0 . 2 5}$ Open $)$ :}

As shown in Fig. 8. (a) and Table 1, the three output pressure curves of the three types of steps are close to each other at $0.25 \mathrm{D}$, indicating that they have a similar dynamic influence on spool movement as in Fig. 8. (b) and Table 1. There is no pressure resonance at $(0.25)$ open.

\section{Second displacement at $\mathrm{X}=0.5 \mathrm{D}(0.5$ Open $)$ :}

As shown in Fig. 9. (a) and Table 2, the two output pressure curves of the one-step and the three-step types of steps are close to each other at $X=0.5 \mathrm{D}$, indicating that they have a similar dynamic influence on spool movement as in Fig. 9. (b) and Table 2. There is no pressure resonance. But the output pressure curve of the two-step type has a pressure resonance at an input pressure equaling 7 bar with an error of 125.43 percent, at 10 bar with an error of 12.76 percent, and at 12 bar with an error of 63.33 percent, indicating a negative dynamic effect on spool movement.

\section{Third displacement at $\mathrm{X}=\mathbf{0 . 7 5 \mathrm { D }}(\mathbf{0 . 7 5}$ Open $)$ :}

The two output pressure curves of the one-step and the three-step types of steps are close to each other at $\mathrm{X}=0.75 \mathrm{D}$, as shown in Fig. 10. (a) and Table 3, indicating that they have a similar dynamic influence on spool movement as in Fig. 10. (b) and Table 3. There is no pressure resonance. But the output pressure curve of the two-step type has a pressure resonance at an input pressure equaling 7 bar with an error of 48.29 percent, indicating a negative dynamic effect on spool movement.

\section{Fourth displacement at $\mathbf{X}=\mathbf{D}$ ( Full Open ):}

The two output pressure curves of the two-step and three-step types of steps are close to each other at $X=$ D, as shown in Fig. 11 . (a) and Table 4, indicating that they have a similar dynamic influence on spool movement as in Fig. 11. (b) and Table 4. There is no pressure resonance. But the output pressure curve of the one-step type has a pressure resonance at an input pressure equaling 9 bar with an error of 13.11 percent, indicating a negative dynamic effect on spool movement.

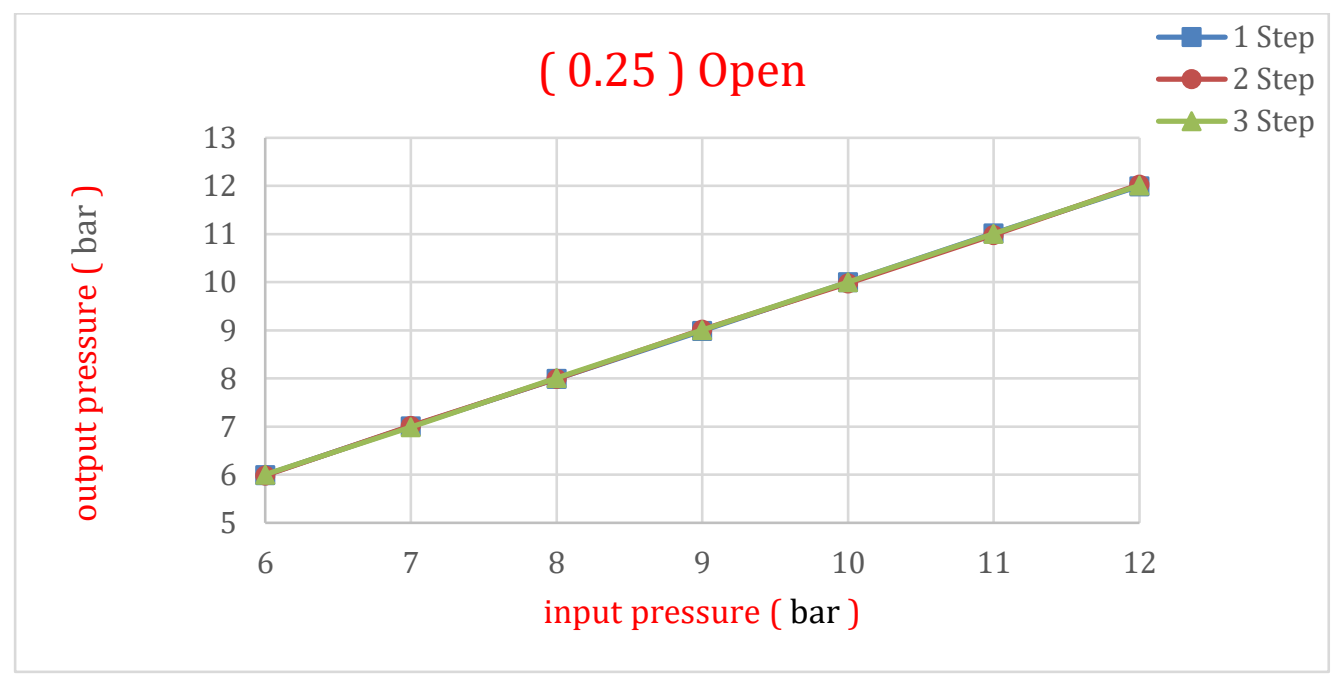

Fig. 8. (a): Curves of the output pressure vs. input pressure at 0.25 open 
International Journal of Advances in Scientific Research and Engineering (ijasre), Vol 8 (2), February -2022

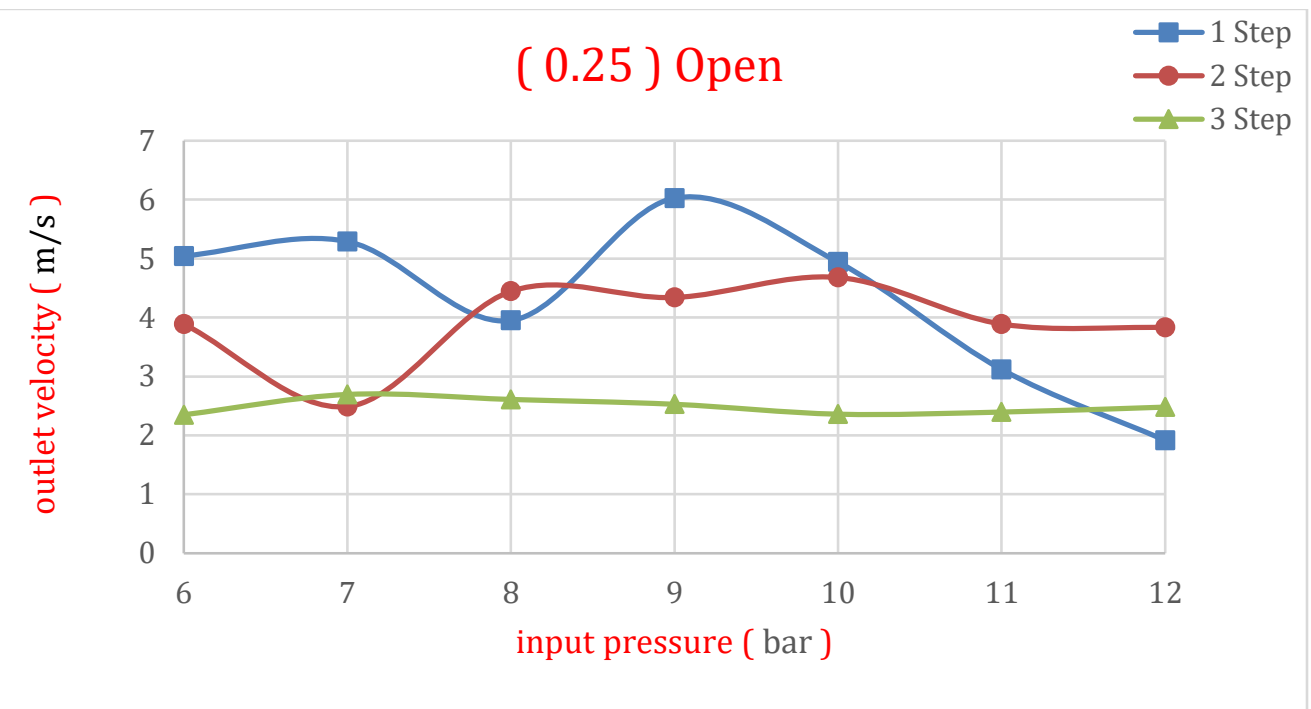

Fig. 8. (b): Curves of the output velocity vs. input pressure at 0.25 open

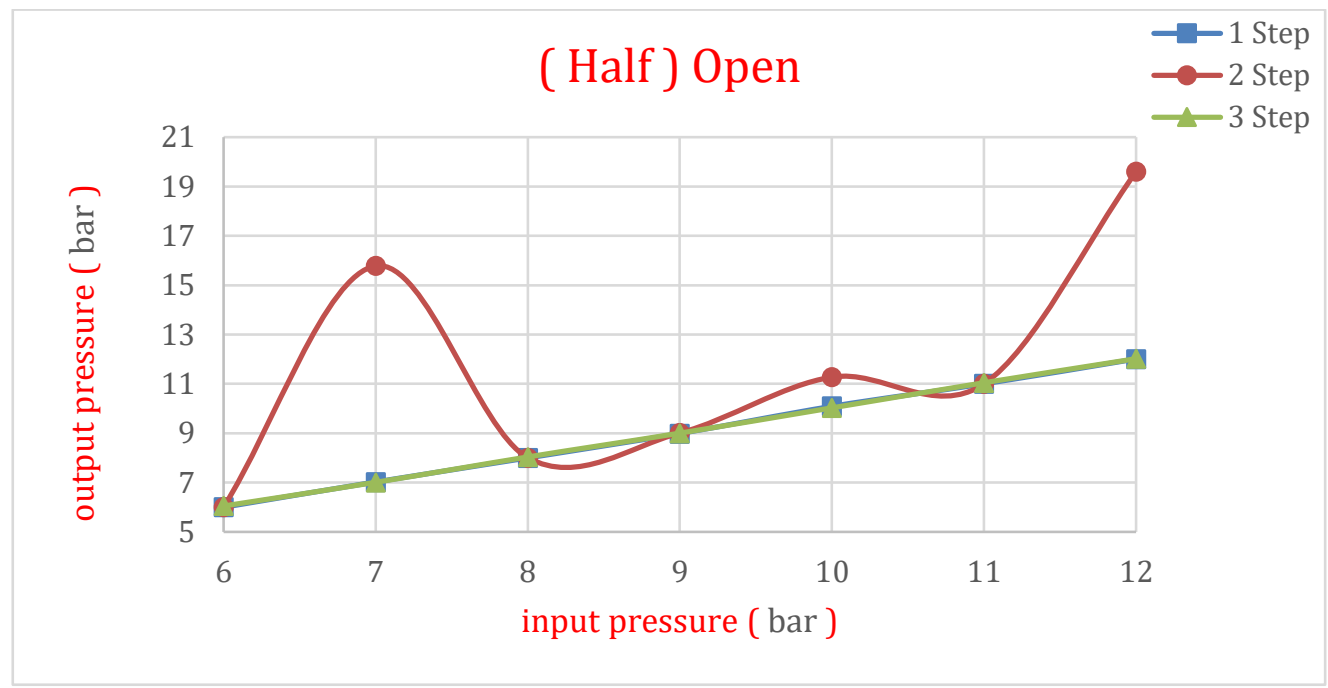

Fig. 9. (a): Curves of the output pressure vs. input pressure at half open

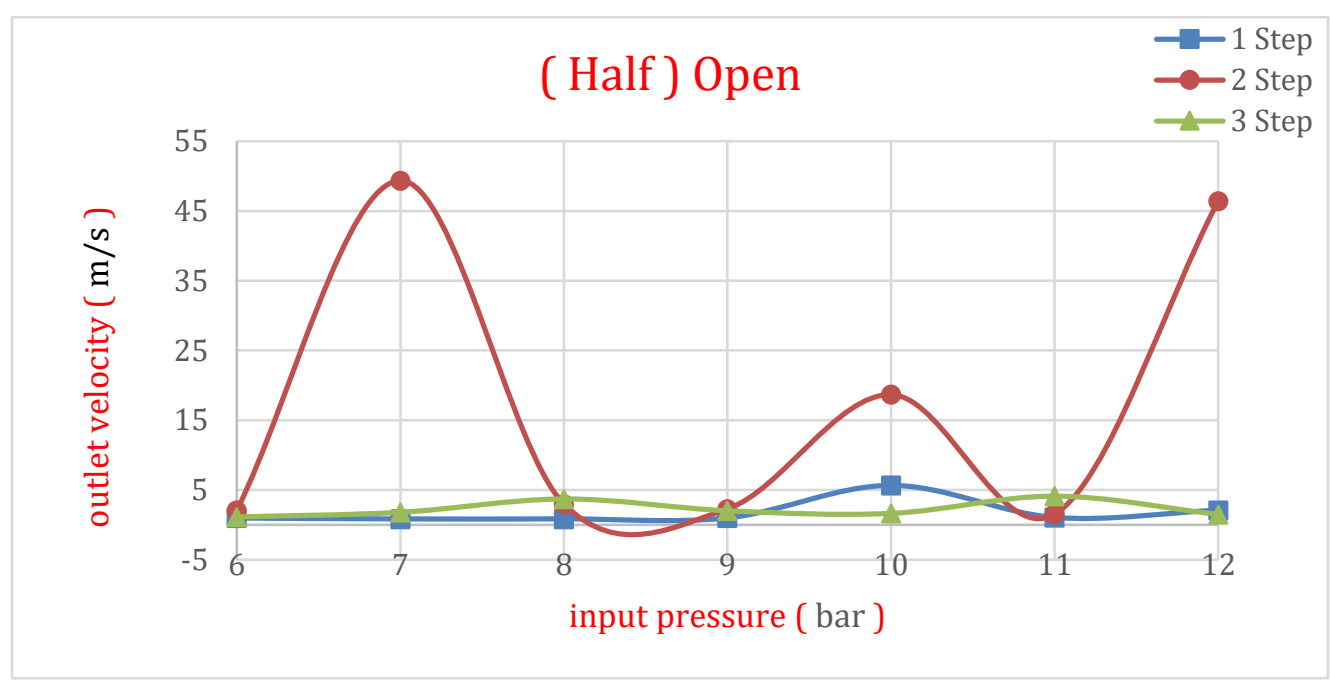

Fig. 9. (b): Curves of the output velocity vs. input pressure at half open 
International Journal of Advances in Scientific Research and Engineering (ijasre), Vol 8 (2), February -2022

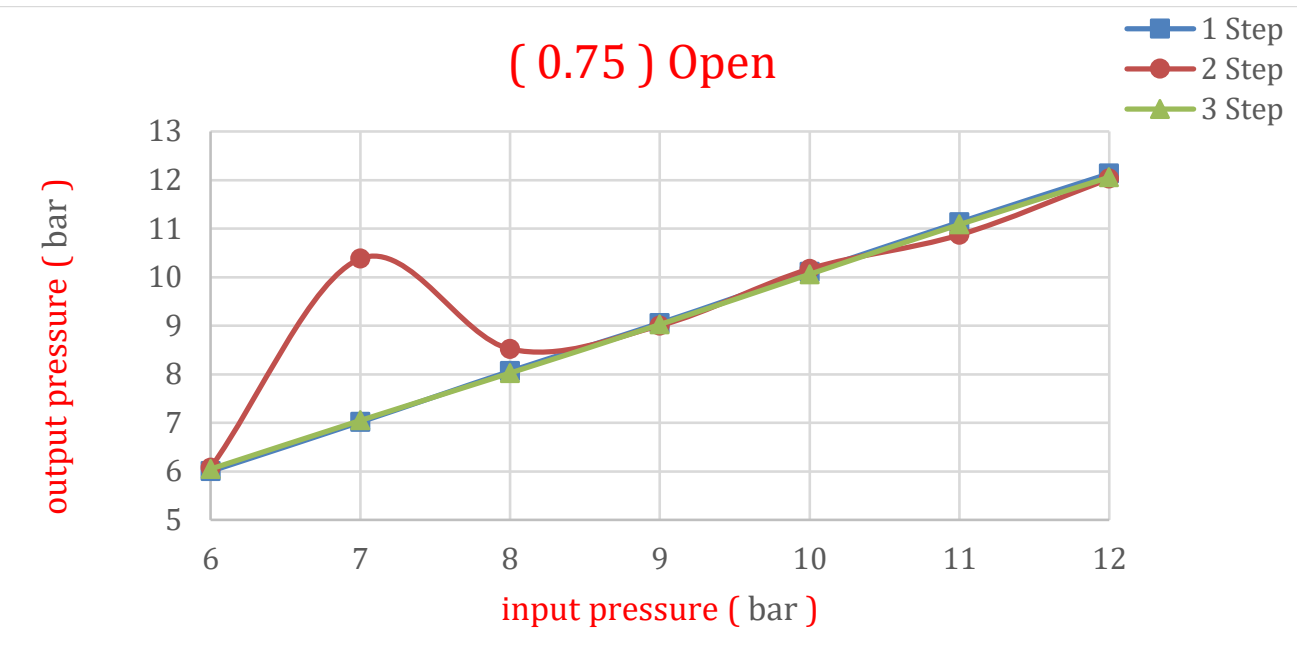

Fig. 10. (a): Curves of the output pressure vs. input pressure at 0.75 open

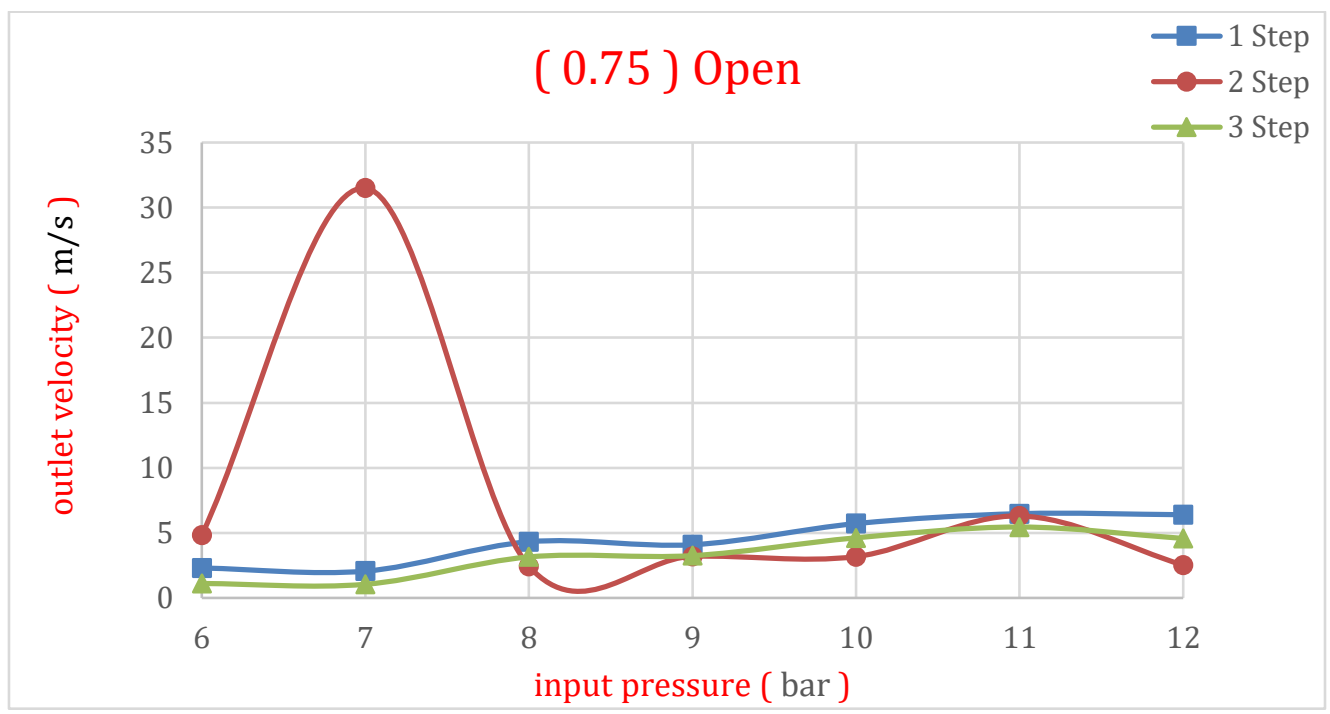

Fig. 10. (b): Curves of the output velocity vs. input pressure at 0.75 open

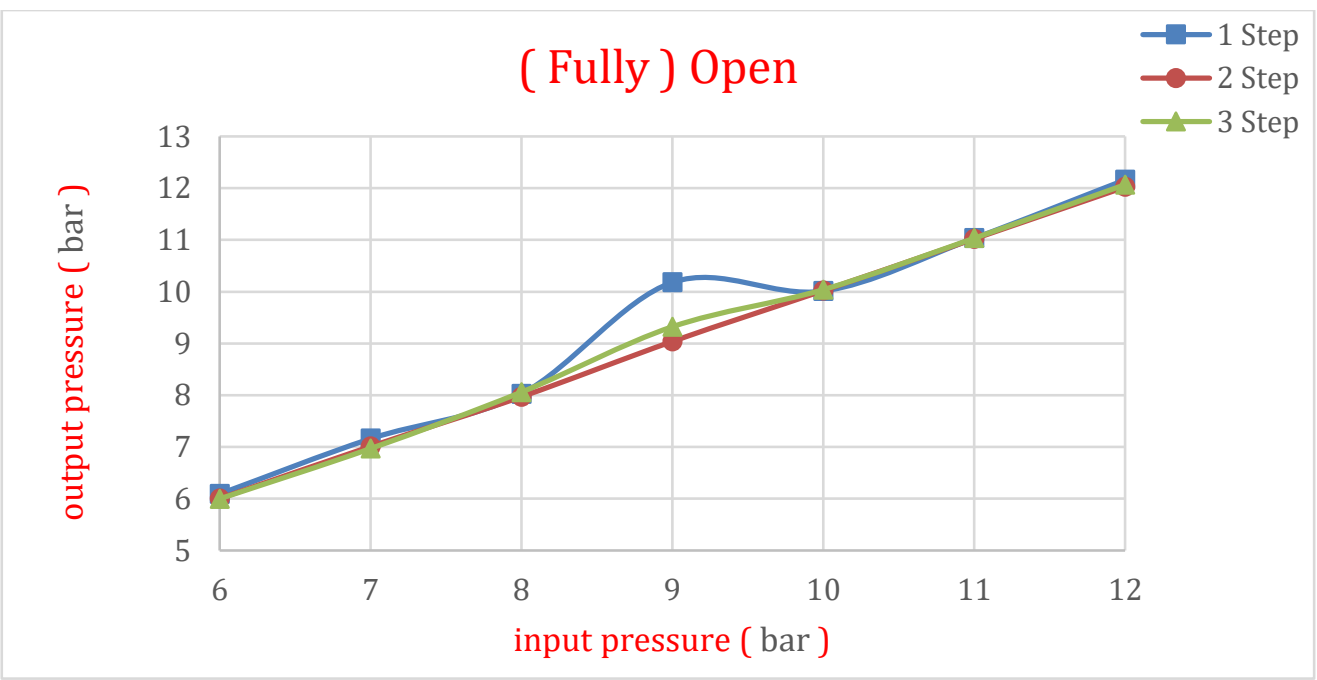

Fig. 11. (a): Curves of the output pressure vs. input pressure at fully open 


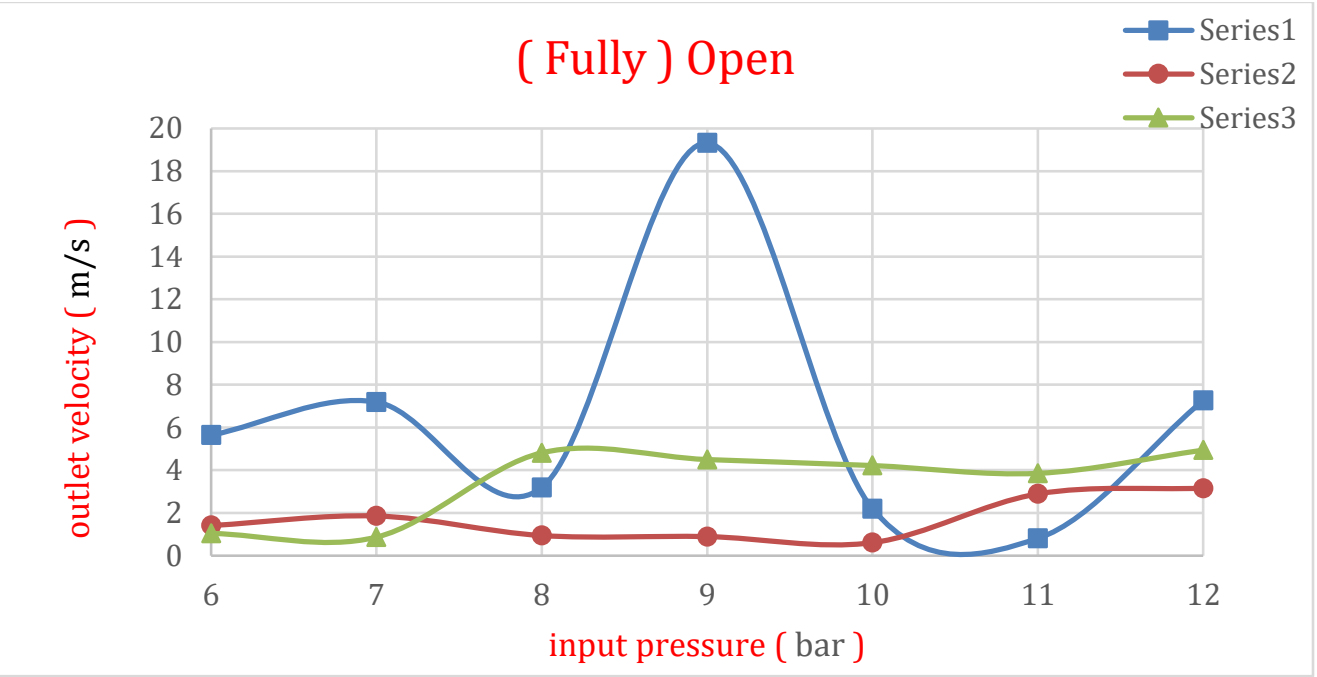

Fig. 11. (b): Curves of the output velocity vs. input pressure at fully open

\section{CONCLUSION}

The flow properties of three distinct shapes, as well as their associated typical structural phases, were investigated using CFD simulation. The findings demonstrated that the step's shape had a substantial impact on the flow. The behaviour of the valve was analyzed theoretically, and the outcomes obtained were compared. The comparison showed that using the spool with three steps was a good design and selection than using one or two steps. Steps minimize the jet of fluid (fuel) flow at the valve inlet and reduce pressure resonance, vortices, and smoothing in the moving spool will be achieved and enhance the dynamic performance. In addition, these steps help to increase valve lifetime. Using CFD approaches to provide solid signals for defining valve design criteria while avoiding costly experimental procedures.

\section{REFERENCES}

[1] Metwally, M., et al., DYNAMIC PERFORMANCE OF AN ELECTROHYDRAULIC SERVO ACTUATOR WITH CONTACTLESS CONTROLLED SPOOL \%J The International Conference on Applied Mechanics and Mechanical Engineering. 2006. 12(12th International Conference on Applied Mechanics and Mechanical Engineering.): p. 334-351.

[2] Samy, M.M., et al. Investigation of Electrohydraulic Control of A Gas Turbine Engine's Inlet Guide Vanes. in International Conference on Aerospace Sciences and Aviation Technology. 2017. The Military Technical College.

[3] Lisowski, E. and J. Rajda, CFD analysis of pressure loss during flow by hydraulic directional control valve constructed from logic valves. Energy Conversion and Management, 2013. 65: p. 285-291.

[4] Lisowski, E., W. Czyżycki, and J. Rajda, Three dimensional CFD analysis and experimental test of flow force acting on the spool of solenoid operated directional control valve. Energy Conversion and Management, 2013. 70: p. 220-229.

[5] Pan, X., G. Wang, and Z. Lu, Flow field simulation and a flow model of servo-valve spool valve orifice. Energy Conversion and Management, 2011. 52(10): p. 3249-3256.

[6] Posa, A., P. Oresta, and A. Lippolis, Analysis of a directional hydraulic valve by a Direct Numerical Simulation using an immersed-boundary method. Energy Conversion and Management, 2013. 65: p. 497-506.

[7] Amirante, R., G. Del Vescovo, and A. Lippolis, Evaluation of the flow forces on an open centre directional control valve by means of a computational fluid dynamic analysis. Energy Conversion and Management, 2006. 47(13): p. 1748-1760.

[8] Viall, E.N. and Q. Zhang. Determining the discharge coefficient of a spool valve. in Proceedings of the 2000 American Control Conference. ACC (IEEE Cat. No. 00CH36334). 2000. IEEE.

[9] Huayong, J.H.F.X.Y. and W.J.C.J.o.M.E. Qingfeng, MEARSUREMENT ON PRESSURE DISTRIBUTION OF NONCIRCULAR OPENING SPOOL VALVE [J]. 2004. 4.

[10] Ji, H., X. Fu, and H.J.J.G.X. Yang, Study on steady flow force of non-circular opening spool valve. 2003. 39(6): p. 13-17.

[11] Ye, Q. and J. Chen, Dynamic analysis of a pilot-operated two-stage solenoid valve used in pneumatic system. Simulation Modelling Practice and Theory, 2009. 17(5): p. 794-816.

[12] Chattopadhyay, H., et al., Analysis of flow structure inside a spool type pressure regulating valve. Energy Conversion and Management, 2012. 53(1): p. 196-204.

[13] Chern, M.-J., C.-C. Wang, and C.-H. Ma, Performance test and flow visualization of ball valve. Experimental Thermal and Fluid Science, 2007. 31(6): p. 505-512. 
[14] Amirante, R., P.G. Moscatelli, and L.A. Catalano, Evaluation of the flow forces on a direct (single stage) proportional valve by means of a computational fluid dynamic analysis. Energy Conversion and Management, 2007. 48(3): p. $942-953$.

[15] Borghi, M., M. Milani, and R. Paoluzzi, Stationary Axial Flow Force Analysis on Compensated Spool Valves. International Journal of Fluid Power, 2000. 1(1): p. 17-25.

[16] Yang, Y., et al. Water hydraulics-A novel design of spool-type valves for enhanced dynamic performance. in 2008 IEEE/ASME International Conference on Advanced Intelligent Mechatronics. 2008. IEEE.

[17] Du, X.W., et al., Effect of throttling grooves structure on cavitation noise. Zhejiang Daxue Xuebao (Gongxue Ban)/Journal of Zhejiang University (Engineering Science), 2007. 41(3): p. 456-460+465.

[18] Ye, Y., et al., Effects of groove shape of notch on the flow characteristics of spool valve. Energy Conversion and Management, 2014. 86: p. 1091-1101. 
International Journal of Advances in Scientific Research and Engineering (ijasre), Vol 8 (2), February -2022

Tables

Table 1. The outlet pressure $\&$ the outlet velocity vs. input pressure at $\mathbf{0 . 2 5}$ open

\begin{tabular}{|c|c|c|c|c|c|c|}
\hline$(0.25)$ open & \multicolumn{2}{|c|}{ 1 step } & \multicolumn{2}{c|}{ 2 step } & \multicolumn{2}{c|}{3 step } \\
\hline $\begin{array}{c}\text { Inlet pressure } \\
(\text { bar })\end{array}$ & $\begin{array}{c}\text { Outlet pressure } \\
(\text { bar })\end{array}$ & $\begin{array}{c}\text { Outlet velocity } \\
(\mathrm{m} / \mathrm{s})\end{array}$ & $\begin{array}{c}\text { Outlet pressure } \\
(\text { bar })\end{array}$ & $\begin{array}{c}\text { Outlet velocity } \\
(\mathrm{m} / \mathrm{s})\end{array}$ & $\begin{array}{c}\text { Outlet pressure } \\
(\text { bar })\end{array}$ & $\begin{array}{c}\text { Outlet velocity } \\
(\mathrm{m} / \mathrm{s})\end{array}$ \\
\hline 6 & 5.994 & 5.044 & 5.985 & 3.89 & 6.003 & 2.35 \\
\hline 7 & 7.01 & 5.29 & 7.014 & 2.489 & 6.99 & 2.6944 \\
\hline 8 & 7.995 & 3.95 & 7.992 & 4.445 & 8.012 & 2.61 \\
\hline 9 & 8.99 & 6.026 & 9.013 & 4.34 & 9.01 & 2.528 \\
\hline 10 & 10.004 & 4.94 & 9.98 & 4.68 & 10.005 & 2.36 \\
\hline 11 & 11.015 & 3.12 & 10.98 & 3.89 & 11.01 & 2.396 \\
\hline 12 & 11.996 & 1.916 & 12.03 & 3.83 & 12.012 & 2.48 \\
\hline
\end{tabular}

Table 2. The outlet pressure \& the outlet velocity vs. input pressure at half open

\begin{tabular}{|c|c|c|c|c|c|c|}
\hline ( Half ) open & \multicolumn{2}{|c|}{ 1 step } & \multicolumn{2}{c|}{ 2 step } & \multicolumn{2}{c|}{3 step } \\
\hline $\begin{array}{c}\text { Inlet pressure } \\
\text { (bar ) }\end{array}$ & $\begin{array}{c}\text { Outlet pressure } \\
\text { (bar) }\end{array}$ & $\begin{array}{c}\text { Outlet velocity } \\
(\mathrm{m} / \mathrm{s})\end{array}$ & $\begin{array}{c}\text { Outlet pressure } \\
\text { (bar ) }\end{array}$ & $\begin{array}{c}\text { Outlet velocity } \\
\text { ( } / \mathrm{s} \text { ) }\end{array}$ & $\begin{array}{c}\text { Outlet pressure } \\
\text { ( bar })\end{array}$ & $\begin{array}{c}\text { Outlet velocity } \\
\text { ( } / \mathrm{s} \text { ) }\end{array}$ \\
\hline 6 & 5.999 & 0.979 & 6.006 & 2.065 & 6.05 & 1.135 \\
\hline 7 & 7.025 & 0.854 & 15.78 & 49.36 & 7.01 & 1.801 \\
\hline 8 & 7.998 & 0.857 & 8.008 & 2.979 & 8.038 & 3.712 \\
\hline 9 & 8.988 & 0.994 & 9.01 & 2.29 & 9.003 & 2.02 \\
\hline 10 & 10.09 & 5.656 & 11.276 & 18.665 & 10.028 & 1.643 \\
\hline 11 & 11.0013 & 1.065 & 11.003 & 1.529 & 11.046 & 4.114 \\
\hline 12 & 12.009 & 2.111 & 19.6 & 46.42 & 12.02 & 1.494 \\
\hline
\end{tabular}

Table 3. The outlet pressure $\&$ the outlet velocity vs. input pressure at $\mathbf{0 . 7 5}$ open

\begin{tabular}{|c|c|c|c|c|c|c|}
\hline$(0.75)$ open & \multicolumn{2}{|c|}{ 1 step } & \multicolumn{2}{c|}{ 2 step } & \multicolumn{2}{c|}{3 step } \\
\hline $\begin{array}{c}\text { Inlet pressure } \\
\text { (bar })\end{array}$ & $\begin{array}{c}\text { Outlet pressure } \\
\text { (bar })\end{array}$ & $\begin{array}{c}\text { Outlet velocity } \\
(\mathrm{m} / \mathrm{s})\end{array}$ & $\begin{array}{c}\text { Outlet pressure } \\
\text { (bar })\end{array}$ & $\begin{array}{c}\text { Outlet velocity } \\
(\mathrm{m} / \mathrm{s})\end{array}$ & $\begin{array}{c}\text { Outlet pressure } \\
\text { (bar })\end{array}$ & $\begin{array}{c}\text { Outlet velocity } \\
(\mathrm{m} / \mathrm{s})\end{array}$ \\
\hline 6 & 6.001 & 2.3 & 6.071 & 4.832 & 6.047 & 1.111 \\
\hline 7 & 7.015 & 2.061 & 10.38 & 31.5 & 7.048 & 1.049 \\
\hline 8 & 8.063 & 4.32 & 8.52 & 2.441 & 8.025 & 3.152 \\
\hline 9 & 9.054 & 4.089 & 9.002 & 3.197 & 9.025 & 3.25 \\
\hline 10 & 10.105 & 5.714 & 10.17 & 3.18 & 10.06 & 4.62 \\
\hline 11 & 11.13 & 6.477 & 10.87 & 6.3 & 11.084 & 5.45 \\
\hline 12 & 12.131 & 6.395 & 12.026 & 2.526 & 12.057 & 4.572 \\
\hline
\end{tabular}

Table 4. The outlet pressure \& the outlet velocity vs. input pressure at full open

\begin{tabular}{|c|c|c|c|c|c|c|}
\hline ( fully) open & \multicolumn{2}{|c|}{ 1 step } & \multicolumn{2}{c|}{ 2 step } & \multicolumn{2}{c|}{3 step } \\
\hline $\begin{array}{c}\text { Inlet pressure } \\
\text { (bar ) }\end{array}$ & $\begin{array}{c}\text { Outlet pressure } \\
\text { (bar) }\end{array}$ & $\begin{array}{c}\text { Outlet velocity } \\
(\mathrm{m} / \mathrm{s})\end{array}$ & $\begin{array}{c}\text { Outlet pressure } \\
\text { (bar })\end{array}$ & $\begin{array}{c}\text { Outlet velocity } \\
(\mathrm{m} / \mathrm{s})\end{array}$ & $\begin{array}{c}\text { Outlet pressure } \\
\text { ( bar })\end{array}$ & $\begin{array}{c}\text { Outlet velocity } \\
\text { ( } / \mathrm{s} \text { ) }\end{array}$ \\
\hline 6 & 6.092 & 5.641 & 6.004 & 1.41 & 5.998 & 1.044 \\
\hline 7 & 7.16 & 7.195 & 7.01 & 1.859 & 6.97 & 0.87 \\
\hline 8 & 8.025 & 3.193 & 7.97 & 0.943 & 8.06 & 4.816 \\
\hline 9 & 10.18 & 19.32 & 9.039 & 0.8945 & 9.323 & 4.5 \\
\hline 10 & 10.012 & 2.2 & 10.02 & 0.61 & 10.04 & 4.22 \\
\hline 11 & 11.033 & 0.81 & 11.02 & 2.892 & 11.033 & 3.855 \\
\hline 12 & 12.16 & 7.27 & 12.022 & 3.16 & 12.068 & 4.943 \\
\hline
\end{tabular}

